University of Nebraska - Lincoln

DigitalCommons@University of Nebraska - Lincoln

2005

\title{
Are Specific Language Impairment and Dyslexia Distinct Disorders?
}

Hugh W. Catts

University of Kansas

Suzanne M. Adlof

University of Kansas

Tiffany Hogan

University of Nebraska - Lincoln, thogan2@unl.edu

Susan Ellis Weismer

University of Wisconsin-Madison

Follow this and additional works at: https://digitalcommons.unl.edu/specedfacpub

Part of the Special Education and Teaching Commons

Catts, Hugh W.; Adlof, Suzanne M.; Hogan, Tiffany; and Weismer, Susan Ellis, "Are Specific Language Impairment and Dyslexia Distinct Disorders?" (2005). Special Education and Communication Disorders Faculty Publications. 13.

https://digitalcommons.unl.edu/specedfacpub/13

This Article is brought to you for free and open access by the Department of Special Education and Communication Disorders at DigitalCommons@University of Nebraska - Lincoln. It has been accepted for inclusion in Special Education and Communication Disorders Faculty Publications by an authorized administrator of DigitalCommons@University of Nebraska - Lincoln. 


\title{
Are Specific Language Impairment and Dyslexia Distinct Disorders?
}

\author{
Hugh W. Catts, Suzanne M. Adlof, and Tiffany P. Hogan \\ University of Kansas, Lawrence
}

\section{Susan Ellis Weismer}

University of Wisconsin-Madison

Corresponding author — Hugh W. Catts, Department of Speech-Language-Hearing, 1000 Sunnyside Avenue, University of Kansas,

Lawrence, KS 66045; email catts@ku.edu

\begin{abstract}
Purpose: The purpose of this study was to determine whether specific language impairment (SLI) and dyslexia are distinct developmental disorders.

Method: Study I investigated the overlap between SLI identified in kindergarten and dyslexia identified in 2nd, 4th, or 8th grades in a representative sample of 527 children. Study 2 examined phonological processing in a subsample of participants, including 2 I children with dyslexia only, 43 children with SLI only, 18 children with SLI and dyslexia, and I65 children with typical language/reading development. Measures of phonological awareness and nonword repetition were considered.

Results: Study I showed limited but statistically significant overlap between SLI and dyslexia. Study 2 found that children with dyslexia or a combination of dyslexia and SLI performed significantly less well on measures of phonological processing than did children with SLI only and those with typical development. Children with SLI only showed only mild deficits in phonological processing compared with typical children.

Conclusions: These results support the view that SLI and dyslexia are distinct but potentially comorbid developmental language disorders. A deficit in phonological processing is closely associated with dyslexia but not with SLI when it occurs in the absence of dyslexia.
\end{abstract}

Keywords: specific language impairment, dyslexia, phonological processing, phonological awareness, nonword repetition

In recent years, there has been considerable interest in the relationship between developmental disorders of oral and written language (Bishop \& Snowling, 2004; Catts \& Kamhi, 2005). The most widely investigated developmental written language disorder is dyslexia, which is characterized by a significant deficit in printed word recognition in the face of adequate instruction and general cognitive abilities (Lyon, Shaywitz, \& Shaywitz, 2003). Research has shown that a phonological processing deficit underlies word-reading difficulties in many children with dyslexia (Fletcher et al., 1994; Gillon, 2004). In the case of oral language, the most frequently studied developmental disorder is specific language im- pairment (SLI). Children with SLI exhibit deficits in semantics, syntax, and discourse in the presence of normal nonverbal cognitive abilities (Leonard, 1998; Tager-Flusberg \& Cooper, 1999).

At first glance, it would seem that SLI and dyslexia are two distinct developmental language disorders; SLI primarily represented by difficulties in semantics, syntax, and discourse, and dyslexia characterized by problems in phonological processing and word reading. However, recent findings suggest there may be a closer association between these developmental language disorders. Children with dyslexia have been shown to have early deficits in semantics and syntax (Gallagher, 
Frith, \& Snowling, 2000; P. Lyytinen, Poikkeus, Laakso, Eklund, \& Lyytinen, 2001; Scarborough, 1990, 1991; Snowling, Gallagher, \& Frith, 2003), and children with SLI have often been noted to have phonological processing deficits and subsequent problems in word recognition (Catts, 1993; Snowling, Bishop, \& Stothard, 2000). These findings have led some to conclude that dyslexia and SLI represent variants of the same developmental language disorder (Kamhi \& Catts, 1986; Tallal, Allard, Miller, \& Curtiss, 1997). However, in a recent review of behavioral, neurological, and genetic evidence, Bishop and Snowling (2004) concluded that SLI and dyslexia are best treated as two different but overlapping developmental disorders. In this article, we present the results from a longitudinal study that provide further evidence for a distinction between SLI and dyslexia.

\section{Dyslexia}

According to the International Dyslexia Association (IDA), dyslexia is a specific learning disability characterized by difficulties with accurate and/or fluent word recognition and spelling (Lyon et al., 2003). The IDA definition further proposes that these difficulties typically result from a deficit in the phonological component of language and are unexpected in relation to age and other cognitive and academic abilities. The phonological difficulty most often associated with dyslexia is a deficit in phonological awareness, one's sensitivity to, or explicit awareness of, the sound structure of language (Stanovich, 1988). It is generally argued that problems in phonological awareness make it difficult for children with dyslexia to learn how to apply the alphabetic principle to decode and spell printed words (Gillon, 2004). Numerous studies have documented a deficit in phonological awareness in children with dyslexia or in children at risk for this disorder (Bradley \& Bryant, 1983; Gallagher et al., 2000; Fletcher et al., 1994; H. Lyytinen et al., 2001).

The phonological processing problems associated with dyslexia also extend to areas other than phonological awareness. Specifically, children with dyslexia often demonstrate problems in phonological memory (Brady, Shankweiler, \& Mann, 1983; Vellutino \& Scanlon, 1982). Among the phonological memory tasks with which children with dyslexia have difficulty is the nonword repetition task, in which participants must store and repeat a phonological sequence that could be a word in the language but is not. Research has shown that children with dyslexia consistently perform less well than control participants on nonword repetition tasks (Brady, Poggie, \& Rapala, 1989; Catts, 1986; Hulme \& Snowling, 1992; Kamhi \& Catts, 1986; Snowling, 1981; van Daal \& van der Leij, 1999; van der Bob \& van der Pijl, 1997). Studies have also demonstrated that heritability for dyslexia is higher when the disorder is combined with a deficit in nonword repetition (Bishop, 2001; Bishop, Adams, \& Norbury, 2004; Raskind, Hsu, Berninger, Thomson, \& Wijsman, 2000). Finally, research suggests a link between deficits in phonological memory and phonological awareness in that both deficits may result from an inefficiency in the formation of phonological representations (Elbro, 1996; Metsala \& Walley, 1998).

Other research indicates that the language problems in dyslexia may go beyond those in phonological processing. Studies show that children with dyslexia may also have problems in semantics, syntax, and discourse (Catts, Fey, Tomblin, \& Zhang, 1999; McArthur, Hogben, Edwards, Health, \& Mengler, 2000; Plaza, Cohen, \& Chevrie-Muller, 2001). For ease of reference, these problems are referred to in this article as oral language difficulties and do not include a phonological processing deficit. Some of these oral language difficulties could be the result of reading problems themselves. Poor readers do not read as much as good readers do, and as a result may not have the same language learning opportunities as do good readers. However, a growing number of studies demonstrate that oral language difficulties are present in children at risk for dyslexia prior to school entry (Gallagher et al., 2000; P. Lyytinen et al., 2001; Scarborough, 1990, 1991). For example, Scarborough (1990, 1991) followed 20 children with a family risk of dyslexia from 30 months through second grade. The at-risk children who later developed dyslexia showed syntactic deficits in terms of reduced mean length of utterance and restricted use of syntactic structures during the preschool years. Whereas these oral language difficulties were present, they were typically not severe enough for children to have been identified as having SLI (Scarborough \& Dobrich, 1990). This has also been the case for other studies that have documented oral language problems in children with a family risk for dyslexia (e.g., Gallagher et al., 2000).

\section{SLI}

Specific language impairment represents a disorder in the development of oral language (Leonard, 1998). It is specific in that children with SLI have nonverbal IQ scores within normal limits and no hearing or socioemotional deficits. The oral language problems observed in SLI include problems in semantics, syntax, and discourse (Paul, 2001). Particular attention has been given to deficits in morpho-syntax (Leonard, 1998). For example, children with SLI have been shown to have problems in the acquisition of tense marking, and this deficit has been posited by some as a psycholinguistic or clinical marker of SLI (Conti-Ramsden, Botting, \& Faragher, 2001; Bedore \& Leonard, 1998; Rice \& Wexler, 1996). 


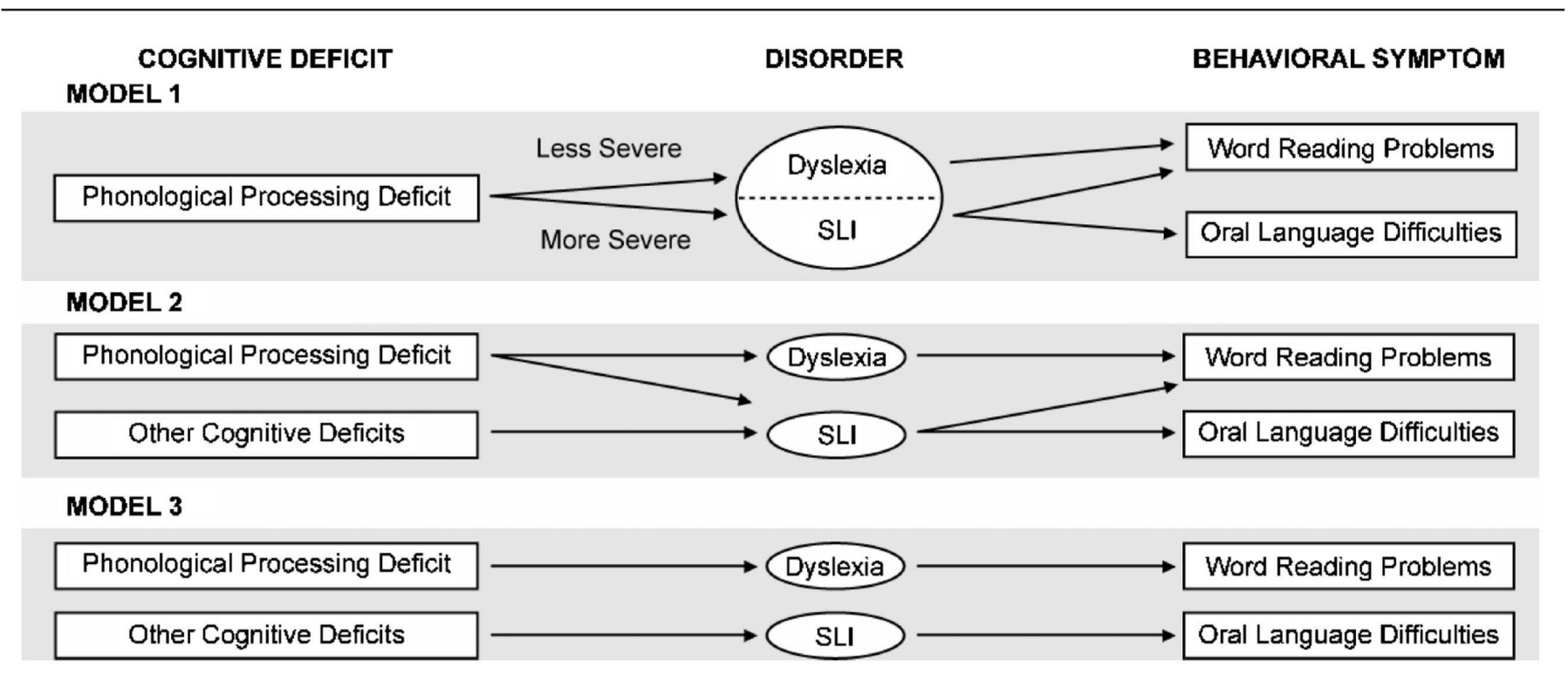

Figure I. Models of the relationship between specific language impairment (SLI) and dyslexia.

Children with SLI have also been reported to have problems in phonological processing. These include deficits in phonological awareness (Briscoe, Bishop, \&Norbury, 2001; Catts, 1993; Joffe, 1998; Nathan, Stackhouse, Goulandris, \& Snowling, 2004; Snowling et al., 2000) and phonological memory (Bishop, North, \& Donlan, 1996; Briscoe et al., 2001; Dollaghan \& Campbell, 1998; Edwards \& Lahey, 1998; Ellis Weismer et al., 2000; Gathercole \& Baddeley, 1990; Kamhi \& Catts, 1986). In fact, considerable attention has been paid to a link between SLI and deficits in phonological memory. Specifically, Gathercole and Baddeley (1990) observed that children with SLI performed poorly on measures of phonological memory, especially nonword repetition. On the basis of their results, they proposed that SLI involves a specific deficit in the phonological loop component of working memory, which causes difficulties in semantic and syntactic development. Furthermore, Bishop et al. (1996) proposed that difficulty in nonword repetition may be a good phenotypic marker for SLI (also see Conti-Ramsden et al., 2001).

Given the problems that children with SLI appear to have in phonological processing, it would be expected that these children would also have difficulties in word reading. Indeed, studies have shown that children with SLI often have problems in learning to recognize printed words (Bishop \& Adams, 1990, Catts, 1993; Catts, Fey, Tomblin, \& Zhang, 2002; McArthur et al., 2000; Snowling et al., 2000; Tallal, Allard, \& Curtiss, 1988). For example, Tallal et al. (1988) found that approximately $67 \%$ of children with SLI at 4 years of age showed low achievement in word recognition at age 8. Silva, Williams, and McGee (1987) also reported evidence of low word reading achievement in children with SLI, but at a lower prevalence rate (approximately 35\%). In addition, McArthur et al. (2000) found in a series of three studies that approximately $50 \%$ of school-age children with SLI concurrently had a specific reading disability characteristic of dyslexia. Snowling et al. (2000) also reported high rates of dyslexia in children with SLI.

\section{Relationship Between Dyslexia and SLI}

Given the documented overlap between SLI and dyslexia, what is the best way to characterize the relationship between these disorders? Three possible models of this relationship are depicted in Figure 1. According to Model 1, dyslexia and SLI are different manifestations of the same underlying cognitive deficit (Kamhi \& Catts, 1986; Tallal et al., 1997). In this model, a phonological processing deficit is responsible for both disorders. The different manifestations (SLI vs. dyslexia), however, result from variations in the severity of the phonological processing deficit. If the deficit is severe, children will show problems in word reading as well as difficulties in oral language (i.e., SLI). If, on the other hand, the deficit is less severe, children will demonstrate problems in word reading and show limited or no problems in oral language (i.e., dyslexia). If Model 1 is correct, there should be a great deal of overlap between SLI and dyslexia. Children with SLI and those with dyslexia should have problems on tasks involving phonological processing and word reading; however, these problems should be more severe in children with SLI.

Model 2 indicates that dyslexia and SLI are partially similar but distinct disorders. A model such as this was proposed by Bishop and Snowling (2004) in a recent review of the literature. According to Model 2, both disor- 
ders are similar in that they are characterized by a phonological processing deficit that underlies word-reading problems. Unlike Model 1, the severity of the phonological deficit is equal, on average, in dyslexia and SLI. The disorders, however, are different in that SLI involves an additional cognitive deficit or deficits, which operates independently of the phonological processing deficit and causes problems in the development of oral language. If this model is accurate, it would be expected that there would be considerable overlap between dyslexia and SLI in that both disorders would have similar problems in phonological processing and word reading. However, the disorders would be distinct in that children with SLI would have difficulties in oral language, and those with dyslexia would show normal or at least low normal development in this area.

Model 3 depicts a third possible relationship between dyslexia and SLI. According to this model, dyslexia and SLI are distinct developmental disorders with different cognitive deficits and behavioral manifestations. As shown in this model, a phonological processing deficit is the core deficit in dyslexia and is responsible for the word reading problems of children with this condition. Children with SLI, on the other hand, have a different deficit(s) at the core of their disability that causes problems in the development of oral language. Unlike Model 2 , in which the overlap results from both disorders showing a deficit in phonological processing, the overlap in Model 3 is due to comorbidity (Caron \& Rutter, 1991). That is, although the disorders are distinct, they are related and sometimes occur together in the same individual. If this view is correct, it would be expected that greater-than-chance overlap should be found between SLI and dyslexia. However, numerous cases should be observed of children with SLI who do not have word reading problems (and a phonological processing deficit) and children with dyslexia who do not have a history of oral language difficulties.

In this article we report the results of two studies that sought to determine which of the above models best characterizes the relationship between dyslexia and SLI. ${ }^{1}$ In Study 1, we used a large longitudinal database to study the overlap between these developmental disorders. This database included measurements of oral language (and IQ) in kindergarten, second, fourth, and eighth grades and assessments of word recognition in second, fourth, and eighth grades. In our analyses, we examined the percentage of children with SLI in kindergarten who had dyslexia in second, fourth, and eighth grades. Conversely, we also determined the percentage of children identified as having dyslexia in second, fourth, or eighth grades who showed SLI in kindergarten.
In both of the above cases, SLI was identified during kindergarten. The decision to identify SLI at this point was based on several factors. First, because SLI is characterized by problems in the development of oral language, it has traditionally been diagnosed during the preschool years (Leonard, 1998; Rice \& Wexler, 1996). Second, it is preschool problems in oral language that have often been argued to be an early manifestation of dyslexia (Scarborough, 2005; Snowling et al., 2003; Tallal et al., 1997). Third, and perhaps most important, by identifying SLI in kindergarten, prior to formal reading instruction, we reduce the possibility that the oral language impairments associated with SLI are the result of dyslexia rather than an early manifestation of the disorder. As noted above, children with dyslexia read less often and thus are not as able to take advantage of the language learning opportunities that accompany reading experience (Stanovich, 1986). This may in turn lead to the development of language problems during the school years (Share \& Silva, 1987). Thus, by identifying oral language impairments in kindergarten, one can reduce the impact of poor reading on this diagnosis.

\section{Study 1: Overlap Between SLI and Dyslexia}

\section{Method \\ Participants}

Children with SLI and children with dyslexia were selected from a population-based sample of children participating in a longitudinal study of language and reading development. The specific criteria used to select participants with SLI and those with dyslexia are described at the end of the Method section. In this section, the participant sample from which these children were drawn is described. This sample included 527 schoolage children. These children originally participated in an epidemiologic study of language impairments in kindergarten children (Tomblin et al., 1997). The epidemiologic investigation used a stratified cluster sample of 7,218 children. This sample was stratified by residential setting (i.e., rural, urban, suburban) and clustersampled by school building. The sample was 33\% rural, $37 \%$ urban, $30 \%$ suburban; $51 \%$ male, $49 \%$ female; and $83 \%$ White, $12.7 \%$ African American, and $4 \%$ other. All available kindergarten children in selected schools were screened for language impairments using a test of 40 items taken from the Test of Language Development2: Primary (TOLD-2:P; Newcomer \& Hammill, 1988). These items had been shown to have high sensitivity for

1 This study provides evidence concerning the relationship between dyslexia and SLI in English-speaking children. Although these disorders are thought to be constitutional in origin, the nature of the spoken language and/or orthography could influence the specific relationship between them. 
the identification of SLI (see Tomblin, Records, \& Zhang, 1996). Children who failed the screening, and a random sample who passed, were given a diagnostic test battery of language abilities and other measures. Data from this assessment were used to estimate the prevalence of language impairments in kindergarten children (Tomblin et al., 1997).

On completion of the epidemiologic study, a subsample of children was solicited to participate in a follow-up longitudinal investigation conducted by the Child Language Research Center (Tomblin, Zhang, Weiss, Catts, \& Ellis Weismer, 2004). Because the primary purpose of the center is the study of language impairments, all children who displayed these impairments on the kindergarten diagnostic battery were asked to participate. Of the 642 children who met this criterion, permission to participate was received for 328 . In addition to these children, a random sample of the children without impairments was recruited. Permission to participate was obtained for 276 nonimpaired children, yielding a total sample of 604 children. These children, segregated by diagnostic category, did not differ significantly in terms of demographic characteristics or language and cognitive abilities from those children who were not asked or did not choose to participate. All children were monolingual English speakers and had no history of sensory deficits or neurological disorders. In addition, no child had been diagnosed with autism or mental retardation in the epidemiologic study.

All the above 604 children completed the kindergarten and second-grade test batteries. Thirty-four children were lost to attrition by fourth grade and another 43 were lost by eighth grade. The latter 77 children did not differ significantly in language or nonverbal cognitive abilities from the remaining 527 children; however, the children who remained in the study throughout the project had significantly higher reading achievement in second grade than those who dropped out. This difference in reading achievement could have influenced the estimate of the prevalence of dyslexia in participants with SLI; however, analyses showed no evidence of such influence. Children with SLI from the sample of $604(\mathrm{~N}$ $=123$ ) had rates of dyslexia in second grade (the only grade in which rates were available for both groups) almost identical to those of the subset of children with SLI who remained in the study through eighth grade $(N=$ 106). Therefore, to better allow for comparisons across grades, children with SLI (and/or dyslexia) were drawn from the 527 children who completed testing through eighth grade.

\section{Materials}

Language. In kindergarten, language abilities were assessed by five subtests of the TOLD-2:P (Newcomer
\& Hammill, 1988) and a narrative story task (Culatta, Page, \& Ellis, 1983). Local norms were used to convert raw scores to $z$ scores. These norms were based on data from 1,502 children who received the kindergarten test battery in the epidemiologic study. The $z$ scores from the TOLD-2:P Picture Identification and Oral Vocabulary subtests were combined to form a vocabulary composite score. The $z$ scores from the TOLD-2:P Grammatic Understanding, Grammatic Completion, and Sentence Imitation subtests were used to form a grammar composite score, whereas $z$ scores from the comprehension and recall portions of the narrative task were used as a narrative composite score. To derive a receptive language composite score, $z$ scores from the Picture Identification, Grammatic Understanding, and narrative comprehension tasks were combined. To obtain an expressive language composite score, $z$ scores from the Oral Vocabulary, Grammatic Completion, Sentence Imitation, and narrative recall tasks were used. An overall language composite score was also calculated using the expressive and receptive language composite scores.

Intelligence. The criteria we used to identify SLI and dyslexia required estimates of nonverbal and Full Scale IQ. As part of the diagnostic battery in kindergarten, children were administered the Block Design and Picture Completion subtests of the Wechsler Preschool and Primary Scale of Intelligence-Revised (Wechsler, 1989). These subtests were combined to form a composite measure of nonverbal IQ (Bishop \& Adams, 1990; LoBello, 1991). Nonverbal IQ was assessed again in second and eighth grades. In second grade, the full Performance scale of the Wechsler Intelligence Scale for Children - III (Wechsler, 1991) was administered. In eighth grade, the Block Design and Picture Completion subtests from the Wechsler Intelligence Scale for Children-III were given.

Full Scale IQ was also estimated in second, fourth, and eighth grades. At each of these grades, the Peabody Picture Vocabulary Test-Revised (PPVT-R; Dunn \& Dunn, 1981) served as an index of verbal intelligence. Scores on the PPVT-R were combined with those on tests of nonverbal IQ to form a composite $z$ score to estimate Full Scale IQ at each grade. Because no measure of nonverbal IQ was available in fourth grade, we combined children's scores on the second grade measure of nonverbal IQ with that on the fourth grade PPVT-R to create an estimate of Full Scale IQ for fourth grade.

Word recognition. The Word Identification and Word Attack subtests of the Woodcock Reading Mastery Tests - Revised (Woodcock, 1987) were administered in second, fourth, and eighth grades. The Word Identification subtest measured participants' ability to accurately pronounce printed English words ranging from high to low frequency of occurrence. The Word Attack sub- 
test assessed participants' ability to read pronounceable nonwords varying in complexity. To form a composite score for word recognition, the standard scores for these subtests were converted to $z$ scores and combined to form a composite $z$ score.

\section{Criteria for SLI}

The criteria we used for SLI were used in the original epidemiologic study (Tomblin et al., 1996). These criteria were developed to be consistent with research findings in child language disorders and to have high sensitivity and specificity when compared to clinical judgments of SLI. The criteria are also similar to those used by many others to identify the disorder (Paul, 2001; Silva, 1980). Our approach is based on a model of language that includes three domains of language (vocabulary, grammar, and narration) and two modalities (receptive and expressive). A composite score is calculated for each domain and modality of language. Children are identified as having a language impairment if their performance on at least two of five language composite $z$ scores fall below $-1.25 S D$ (approximately the 10th percentile based on local norms). This criterion is approximately equal to having an overall language composite $z$ score of below 1.14 SD (Tomblin et al., 1996). Furthermore, children are considered to have a "specific" language impairment (SLI) if they also demonstrate normal or above-normal nonverbal IQ (>-1 SD) and normal sensory and socioemotional development (Stark \& Tallal, 1981).

Data from the kindergarten diagnostic battery were used to identify children with SLI. When the above criteria were applied to these data, 106 of the 527 children in the sample were identified as having SLI. These children had a mean language composite standard score (based on local norms) of $76.9(S D=5.4)$ and a mean nonverbal IQ standard score of $99.4(S D=8.6)$ in kindergarten.

\section{Criteria for Dyslexia}

We used multiple sets of criteria for dyslexia to capture the variability in the way the disorder has been defined. Our most liberal definition of dyslexia required low achievement in word recognition ability alone (Siegel, 1989). This was referred to as the low-achievement definition. We operationalized low achievement as performance of at least $1 S D$ below the mean on the composite measure of word recognition. This cutoff value is consistent with that frequently used by other researchers in the study of reading problems in young children (McArthur et al., 2000; Meyer, Wood, Hart, \& Felton, 1998; Snowling et al., 2003) and represents a compromise criterion level compared with that found in more liberal definitions (25th percentile; Fletcher et al., 1994; Stanovich \& Siegel, 1994) or in more conservative defini- tions of reading disabilities (1.5 SD; Badian, McAnulty, Duffy, \& Als, 1990). It is also comparable to the severity level of the overall language composite score reflected in our criteria for SLI.

Whereas dyslexia has occasionally been defined on the basis of low achievement alone, most traditional definitions require that low achievement occur in the presence of normal intelligence (Vellutino, Scanlon, \& Lyon, 2000; Wimmer, Mayringer, \& Landerl, 2000) or that a significant discrepancy exist between reading level and intelligence (Frankenberger \& Fronzaglio, 1991; Rutter \& Yule, 1975; B. A. Shaywitz, Fletcher, Holahan, \& Shaywitz, 1993). Therefore, we used several definitions that referenced intelligence. First, in the $I Q-$ cutoff definition, children were considered to have dyslexia if they had low achievement in word reading ( $<-$ $1 S D)$ and scored above a cutoff value $(-1 S D)$ in their measured intelligence. Separate analyses were undertaken using either estimates of Full Scale IQ or nonverbal IQ as the index for intelligence. Whereas Full Scale IQ is most often used in defining dyslexia (Pennington, Gilger, Olson, \& DeFries, 1992; S. E. Shaywitz, Shaywitz, Fletcher, \& Escobar, 1990), a few researchers have used nonverbal IQ in studies of the reading outcomes of children with SLI (e.g., Bishop \& Adams, 1990). The latter approach, although less common, reduces the role of verbal intelligence in identifying dyslexia and therefore might be expected to lead to more children with a history of SLI being identified as having dyslexia than if Full Scale IQ is used.

Second, we used an IQ-achievement discrepancy definition. The IQ-cutoff definition assures that children with dyslexia have normal intelligence but does not always result in a significant discrepancy between reading ability and intelligence. To address this issue, it is common to use an IQ-achievement discrepancy approach, especially one that controls for the correlation between reading and intelligence (Snowling et al., 2000). In this approach, children are identified as having dyslexia if their achievement level is significantly below that predicted by their intelligence. In operationalizing this approach, we used regression equations based on data from the entire sample. Estimates of Full Scale IQ and nonverbal IQ were each used to predict word recognition scores. Participants were identified as having dyslexia if their actual word recognition score was more than $1 S D$ below their predicted word recognition score. Finally, we also calculated prevalence rates for dyslexia using criteria that required that children not only show the above discrepancy but also have low achievement in word recognition. Such an approach has been suggested in order to eliminate children from the category of dyslexia who have normal word recognition, but at a level significantly below that predicted by their intelligence (Dykman \& Ackerman, 1992). 
Table I. Percentages of children with specific language impairment in kindergarten $(\mathrm{N}=106)$ who met various criteria for dyslexia.

\begin{tabular}{lccc}
\hline Criteria & 2nd grade & 4th grade & 8th grade \\
\hline Low achievement & 33.0 & 31.1 & 35.8 \\
$\begin{array}{l}\text { Low achievement } \\
\text { + IQ cutoff }\end{array}$ & & & \\
Full Scale IQ & 18.9 & 19.8 & 20.8 \\
Nonverbal IQ & 26.4 & 25.5 & 26.4 \\
IQ discrepancy & & & \\
Full Scale IQ & 17.9 & 17.0 & 18.8 \\
Nonverbal IQ & 25.5 & 27.4 & 29.2 \\
IQ discrepancy & & & \\
$\quad+$ low achievement & & & \\
Full Scale IQ & 17.9 & 17.0 & 17.9 \\
Nonverbal IQ & 24.5 & 24.5 & 28.3 \\
\hline
\end{tabular}

An estimate of Full Scale IQ was used that included the Peabody Picture Vocabulary Test-Revised as a measure of Verbal IQ.

\section{Results}

In the first set of analyses, we examined the prevalence of dyslexia in second, fourth, and eighth grades among children with SLI in kindergarten. The percentages of children with SLI in kindergarten who met the various criteria for dyslexia at each grade are shown in Table 1. These results indicated that approximately one third of the children with SLI had low achievement in word recognition in second, fourth, and eighth grades; however, only about $19 \%$ to $21 \%$ of the children met the low achievement plus Full Scale IQ-cutoff criteria for dyslexia. As expected, slightly higher prevalence rates $(25 \%-26 \%)$ were found when nonverbal IQ rather than Full Scale IQ was used as the IQ-cutoff criterion. The prevalence rates and the difference between estimated Full Scale IQ- and nonverbal IQ-based criteria were essentially the same when the regression-based IQ-discrepancy criteria were used. In addition, similar results were observed when the requirement of low achievement was added to the regression-based IQ-discrepancy criteria. The latter finding indicates that there were very few children with SLI who had reading achievement significantly below that predicted by IQ but still in the normal range.

Given the relatively low rate of dyslexia among children with SLI, it is important to ask if this rate is higher than the base rate of the disorder in the general population. Our calculations showed that the base rate of dyslexia (using the Full Scale IQ-discrepancy and low achievement criterion in fourth grade) in our sample of 527 children was $8.6 \%$. A two-sample binomial test demonstrated that the observed prevalence of dyslexia among children with SLI (17\%) was significantly higher than this base rate $(\mathrm{z}=3.1, p=.002)$. Also, when similar criteria involving nonverbal IQ are used, the observed rate of dyslexia in children with SLI $(24.5 \%)$ was significantly higher than the base rate of this condition in our population $(9.7 \% ; z=4.1, p<.001)$. Results were similar when we compared rates based on dyslexia in second and eighth grades.

In a second set of analyses, we examined the relationship between SLI and dyslexia from the opposite perspective; that is, we determined the percentage of children with dyslexia in second, fourth, and eighth grades who met the criteria for SLI in kindergarten. For this analysis, we used the regression-based IQ-discrepancy plus low achievement criteria. Estimates of Full Scale and nonverbal IQ were used in separate calculations. Using criteria involving Full Scale IQ, we identified from our sample of 527 participants 72 children with dyslexia in second grade, 74 in fourth grade, and 68 in eighth grade. Using nonverbal IQ, we identified 85 children with dyslexia in second grade, 89 in fourth grade, and 75 in eighth grade. For each method, there was considerable overlap in those children identified with dyslexia across grades. Approximately $70 \%$ to $75 \%$ of the children identified as having dyslexia at a given grade also met the criteria for dyslexia in at least one of the other grades.

To calculate the percentage of children with dyslexia who had SLI in kindergarten, we used weighted scores. Such a procedure was necessary to reduce the bias that is introduced by the fact that the sample from which we identified children with dyslexia $(N=527)$ had a higher percentage of children with SLI in kindergarten than would be found in the general population. This bias could lead to an overestimation of the prevalence of SLI in children with dyslexia. To reduce this bias, we determined how likely it was that a child in our sample of 527 children with his or her gender, language, and nonverbal profile would have participated in the representative sample seen in the epidemiologic study. Then, each child's scores were weighted accordingly. In other words, although our sample contained more children with language impairments than would be found in a representative sample, the scores of these children were given proportionally less weighting to assure the representativeness of the results. ${ }^{2}$

Our analyses showed that a relatively small percentage of children identified with dyslexia in second,

2 For example, the epidemiologic study estimated that boys with SLI (no nonverbal deficits) compose $3.9 \%$ of the general population. In our sample, however, these children composed $12.1 \%$. To assure that the children from this group did not contribute disproportionately to our results, we adjusted their scores by weighting them by a constant that was equal to the expected prevalence of these children (3.9\%) divided by their actual prevalence in our sample $(12.1 \%$; constant $=.322)$. 
Table 2. Percentage of children with dyslexia in second, fourth, and eighth grades (based on IQ discrepancy and low achievement criteria) who had specific language impairment in kindergarten.

\begin{tabular}{lccr}
\hline Discrepancy & 2nd Grade & 4th Grade & 8th Grade \\
\hline Full Scale IQ & 15.4 & 14.8 & 16.5 \\
Nonverbal IQ & 19.4 & 19.1 & 19.3 \\
\hline
\end{tabular}

An estimate of Full Scale IQ was used that included the Peabody Picture Vocabulary Test-Revised as a measure of verbal IQ.

fourth, or eighth grades met the criteria for SLI in kindergarten. The data in Table 2 show that $14.8 \%$ to $16.5 \%$ of the children with dyslexia based on estimated Full Scale IQ discrepancy (and low achievement) had SLI in kindergarten. A slightly higher, but still low, rate (19\%) was observed when dyslexia was based on nonverbal IQ-discrepancy and low achievement criteria. We again examined whether these prevalence rates were significantly higher than would be expected, given the base rate of SLI in our sample. A series of two-sample binomial tests showed that the observed rates of SLI in children with dyslexia based on estimated Full Scale IQ discrepancy plus low achievement were significantly higher than the base rate of the disorder in second and eighth grades $(z \mathrm{~s}=2.0$ and 2.2, $p<.05)$. The difference between the observed rate and base rate at fourth grade approached but did not reach statistical significance $(z$ $=1.9, p=.057)$. Significant differences were found between the observed rates and base rates at all three grades when the nonverbal IQ-discrepancy plus low achievement criteria for dyslexia were used $(z \mathrm{~s}=2.9-$ $3.1, p<.005)$.

\section{Discussion}

These results demonstrate a somewhat limited but statistically significant overlap between dyslexia and SLI. About one third of children with SLI in kindergarten met the most liberal criteria for dyslexia in later grades. If more conservative (and more widely used) criteria involving reference to IQ were used, fewer children with SLI could be identified as having dyslexia. These data showed that $17 \%$ to $29 \%$ of children with SLI in kindergarten met IQ-referenced definitions of dyslexia in the school grades. A slightly higher rate of dyslexia was found when nonverbal IQ was used as a benchmark than when estimated Full Scale IQ was used. Again, this difference was expected because children with SLI generally have lower verbal than nonverbal IQs and thus should show less of an IQ-achievement discrepancy when an estimate of verbal IQ is included in the IQ benchmark.

The prevalence rates of dyslexia in children with SLI that we observed are lower than those found in many other studies (e.g., McArthur et al., 2000; Snowling et al., 2000; Tallal et al., 1988). Various differences between our study and those of others could account for this discrepancy. One primary difference concerns the way participants were recruited. We used a quasi-random approach to select children from a representative population based sample. Most other studies in this area have used convenience sampling techniques to select participants largely from clinical populations (e.g., McArthur et al., 2000; Snowling et al., 2000). Whereas the latter procedures are common in clinical research, they often result in the recruitment of participants with more severe disorders and concomitant conditions than participants who are obtained through population-based sampling (Berkson, 1946). Thus, in the case of studies of SLI, this procedure could lead to the inclusion of children with more severe language impairments and a higher incidence of dyslexia than in the present investigation. One other investigation has used a population-based sampling procedure like ours and reported data on the reading outcomes of children with SLI. In this study, Silva et al. (1987) identified children with SLI (at or below the 5th percentile on tests of language) from a population of approximately 1,000 three-year-olds. When these children were seen at ages 7,9 , and 11 years, $44.1 \%, 30.4 \%$, and $30.6 \%$, respectively, were found to show low achievement in word recognition. No data were provided concerning the proportion of the children that met IQ-referenced criteria for dyslexia. Nevertheless, the rates of low achievement that they report are comparable to those observed in the present study.

There is at least one other important difference between our study and some other investigations. In the present study, we examined the incidence of dyslexia during the elementary and middle school grades in children identified as having SLI in kindergarten. In the studies reported by McArthur et al. (2000), SLI and dyslexia were identified concurrently during the early elementary school grades. As such, the language problems observed in these studies could have been influenced in part by poor reading achievement, which in turn could have led to a higher overlap of the disorders. We chose to identify SLI prior to reading instruction to limit the impact that a reading disability could have on the development of language problems.

Besides examining the prevalence of dyslexia in children with SLI, we also looked retrospectively at the prevalence of SLI in children identified as having dyslexia. Our results indicated that only approximately $15-20 \%$ of children identified with dyslexia (in second, fourth, or eighth grades) met the criteria for SLI in kindergarten. Such a prevalence rate is lower than that reported by some investigators. Specifically, McArthur et al. (2000) found in a series of four studies that an average of $55 \%$ of children with dyslexia also had significant oral language impairments (met criteria for SLI similar 
to ours). Again, this higher rate is likely influenced by the way participants were recruited. Children with dyslexia in the studies reported by McArthur et al. (2000) were selected by convenience sampling from clinical populations. Such a procedure could have led to participants with more severe reading problems and a higher rate of SLI.

McArthur et al.'s (2000) studies also used concurrent identification of dyslexia and SLI in school-age children. As noted above, such a design could result in a higher degree of overlap between SLI and dyslexia than was found in our study. This conclusion is supported by other studies that have used a design like ours, in which language problems have been observed during preschool prior to the emergence of reading disabilities (Gallagher et al., 2000; P. Lyytinen et al., 2001; Scarborough, 1990, 1991; Snowling et al., 2003). These studies identified children who were at high risk for dyslexia on the basis of a family history of reading disabilities. Results showed that at-risk children who later developed dyslexia often had oral language problems during the preschool years. These problems, however, tended to be rather mild and sometimes disappeared by school entry (Scarborough, 1990; Gallagher et al., 2000). Seldom were language problems severe enough for the children to be diagnosed as having SLI. For example, Gallagher et al. (2000) reported that only 9 of $63(14 \%)$ at-risk children performed at least $1 S D$ below the mean in language abilities (no information was provided concerning nonverbal IQ). Whereas some of these at-risk children did not develop dyslexia in the school years, the proportion that had SLI is still quite low and, in fact, no greater than would be expected in the general population given the criteria they used.

Finally, a word of caution is warranted in terms of the implications of Study 1 for clinical/educational practice. Our findings of a limited overlap between SLI and dyslexia should not diminish the importance of oral language deficits in reading disabilities. This limited overlap was observed between two specific and rather narrowly defined clinical categories in children selected from a population-based sample. Children with SLI who are referred for services in the schools or in clinics are likely to have a greater incidence of dyslexia than we observed. In addition, many children with language impairments that cooccur with nonverbal cognitive deficits or are not severe enough to meet our criteria of SLI go on to have word reading problems like those seen in dyslexia. Many others experience significant problems in reading comprehension (Catts et al., 2002). As such, oral language deficits should remain an important early indicator of risk for reading disabilities and should be addressed with appropriate clinical/educational intervention.

\section{Study 2: Phonological Processing in SLI and Dyslexia}

The results from Study 1 showed a statistically significant overlap between SLI and dyslexia. However, this overlap was rather limited. Only a small percentage of children with SLI in kindergarten met the criteria for dyslexia in the school grades and, conversely, only a small percentage of children with dyslexia in the school grades met the criteria for SLI in kindergarten. Given that the overlap between SLI and dyslexia is limited, we are left with the question of how children with these disorders could be characterized by the same deficits in phonological processing. Recall that research has often shown that children with SLI and those with dyslexia have deficits in phonological awareness and phonological memory (Catts, 1993; Fletcher et al., 1994; Kamhi\& Catts, 1986; Snowling, 1981). One possibility for this puzzling set of findings may be that studies of phonological processing have often included heterogeneous samples involving a mix of children, some with both SLI and dyslexia and some with SLI only. Such studies could show differences between the target population and typically developing children when in fact a phonological processing deficit is primarily characteristic of one disorder and not the other. The disorder most likely to be associated with a phonological processing deficit is dyslexia. Recall that such a deficit is thought to be the proximal cause of word reading problems in dyslexia (Lyon et al., 2003). Children with SLI in the absence of dyslexia may not have problems in phonological processing; however, because of the partial overlap (and borderline cases of overlap) of SLI and dyslexia, it is likely that when a group of children with SLI are selected and compared to a group of typically developing children, significant differences might be found in phonological processing. In Study 2, we examined this issue by investigating phonological processing in children identified with SLI only, dyslexia only, both SLI and dyslexia, and neither of the disorders.

\section{Method}

\section{Participants}

The participants in this study were a subsample of those identified with SLI and/or dyslexia in Study 1. Four groups were selected. One subgroup (SLI only) consisted of all children with SLI in kindergarten who had normal reading achievement in fourth grade (word recognition composite score above the 40th percentile; $N$ $=43$ ). A second subgroup (SLI/dyslexia) was composed of all participants who had SLI in kindergarten and who also met the regression-based Full Scale IQ-discrepancy and low achievement criteria $(N=18)$. A third subgroup 
(dyslexia only) consisted of all children with dyslexia in fourth grade (same criteria as above) who had normal language in kindergarten (i.e., did not meet the criteria for SLI or a nonspecific language impairment; $N$ $=21$ ). A final subgroup (normal) included all children who had normal language in kindergarten (same criteria as above) and normal reading achievement in fourth grade (i.e., same criterion as above; $N=165$ ). Fourth grade reading achievement was used for participant selection because it represented the intermediate point in our reading achievement data. The criteria for SLI and normal language status were again based on kindergarten language scores for the same reasons discussed in Study 1.

The language and word recognition scores of each of the subgroups are displayed in Table 3. The kindergarten language and fourth grade word recognition composite scores are shown to highlight group differences and similarities, some of which were imposed by subgroup selection criteria, while others were not. Analyses of variance (ANOVAs) indicated subgroup differences in language, $F(3,243)=102.7, p<.01$, and word recognition scores, $F(3,243)=243.1, p<.01$. Tukey honestly significant difference tests for unequal Ns demonstrated that the SLI-only and the SLI/dyslexia subgroups had significantly lower language composite scores than the dyslexia-only $(p<.01, d \mathrm{~s}=0.81$ and 0.82 , respectively) and normal subgroups $(p<.01, d=1.73)$. Tukey tests also demonstrated that the dyslexia-only and SLI/dyslexia subgroups had significantly lower word recognition composite scores than the SLI-only $(p<.01, d \mathrm{~s}=1.94$ and 2.41, respectively) and normal subgroups $(p<.01, d \mathrm{~s}$ $=2.17$ and 2.64, respectively). Both of these sets of differences, of course, are expected on the basis of subgroup selection criterion. Other similarities and differences in group comparisons were not predetermined by participant selection criteria. Group comparisons showed that the SLI-only and SLI/dyslexia subgroups did not differ significantly in their language composite scores $(p>$ $.05, d=0.01$ ); however, the dyslexia only subgroup did have a significantly lower language score than the normal subgroup $(p<.001, d=0.92)$. In the case of word recognition, the SLI-only and normal control groups did not differ significantly $(p>.05, d=0.23)$, but a signifi- cant difference was observed between the SLI/dyslexia and the dyslexia subgroups $(p<.05, d=0.47)$.

Materials

The same measures of language, intelligence, and word recognition that were used to identify children with SLI and dyslexia in Study 1 were used to select participants in this study. In addition, measures of phonological awareness and phonological memory were administered to the participants.

Phonological awareness. A syllable/phoneme deletion task was given to participants in kindergarten and second and fourth grades. This task required children to repeat a real word produced via live voice by a trained examiner. The examiner then instructed the participant to say the word again but to delete a designated syllable or phoneme. The kindergarten version included 21 items that required the deletion of the initial syllable or phoneme (Catts, Fey, Zhang, \& Tomblin, 2001). In second and fourth grades, 9 additional items were added that required the deletion of a final consonant or member of a final consonant cluster. The score was the total number of items produced correctly.

In eighth grade, a more complex phoneme deletion task, adapted from Gayan and Olson (2003), was administered to participants. It required participants to repeat 46 nonwords individually and then delete a phoneme to derive a real word. The phoneme to be deleted was a singleton consonant or a consonant in a two- or three consonant cluster. Nonwords were presented via headphones and a high-quality audio recorder, and the participants' responses were recorded. The score was the number of items correct or partially correct (partial credit was given for responses that were incorrect but phonetically similar). The scores from both phonological awareness tasks were converted to standard scores based on the weighted means and standard deviations of the entire sample.

Phonological memory. A nonword-repetition task, which was administered in second and eighth grades, served as a measure phonological memory. This task was developed by Dollaghan and Campbell (1998) and consisted of 16 nonwords ranging from one to four syl-

Table 3. Language and word recognition profiles of Study 2 subgroups.

\begin{tabular}{|c|c|c|c|c|c|c|c|c|}
\hline & \multicolumn{2}{|c|}{$\begin{array}{l}\text { SLI only } \\
(n=43)\end{array}$} & \multicolumn{2}{|c|}{$\begin{array}{l}\text { Dyslexia only } \\
\qquad(n=2 \mathrm{I})\end{array}$} & \multicolumn{2}{|c|}{$\begin{array}{l}\text { SLI and dyslexia } \\
\quad(n=18)\end{array}$} & \multicolumn{2}{|c|}{$\begin{array}{c}\text { Normal } \\
(n=165)\end{array}$} \\
\hline & $M$ & $S D$ & M & $S D$ & $M$ & $S D$ & $M$ & $S D$ \\
\hline Language $(\mathrm{K})$ & 77.0 & $5.6 \mathrm{a}$ & 90.4 & $8 . I_{b}$ & 76.9 & $5.9 a$ & 106.5 & $13.2_{c}$ \\
\hline Word recognition (4th grade) & 105.7 & $6 . \mathrm{I}_{\mathrm{a}}$ & 75.1 & $6.4_{b}$ & 67.7 & $12 . I_{c}$ & 109.3 & $7.9 \mathrm{a}$ \\
\hline
\end{tabular}

Means in the same row that do not share subscripts differ at $p<.05$ in Tukey honestly significant difference test for unequal Ns. SLI $=$ specific language impairment; $\mathrm{K}=$ kindergarten. 


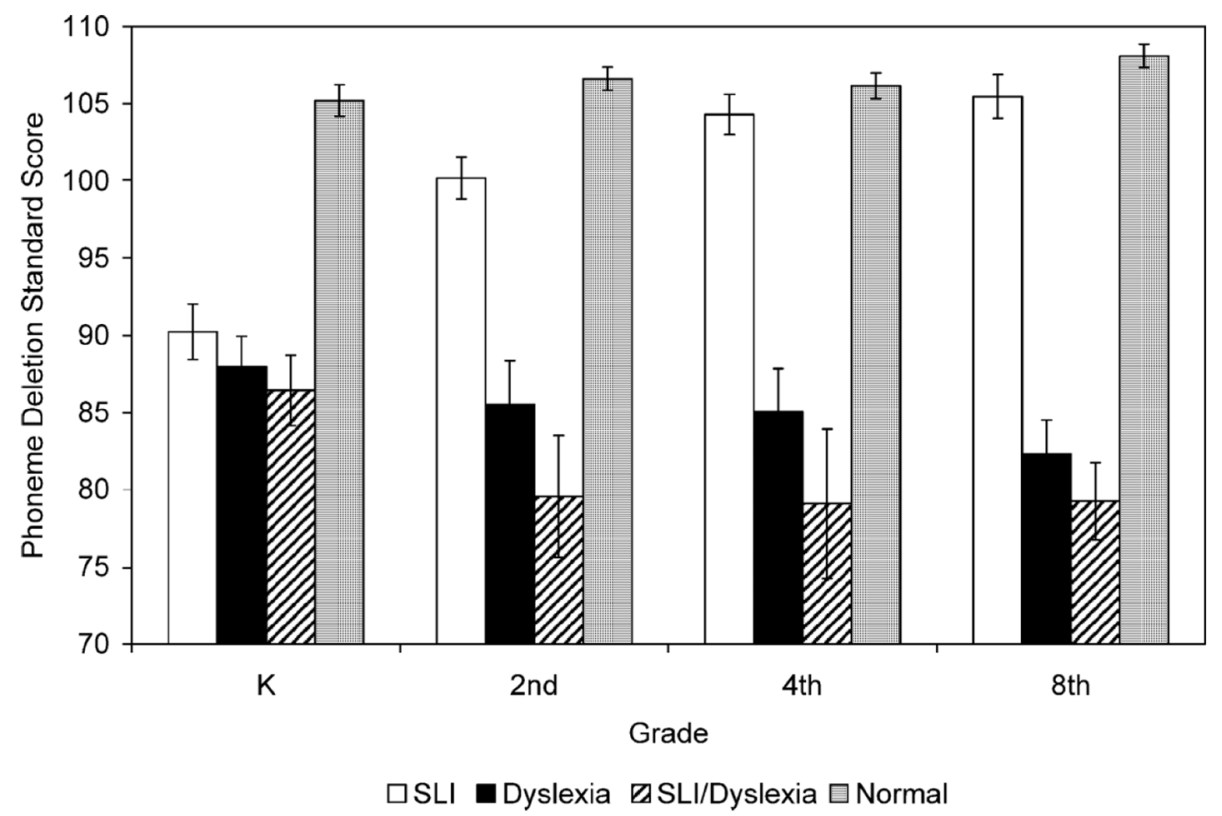

Figure 2. Phonological awareness performance of subgroups in kindergarten and the second, fourth, and eighth grades.

lables in length (four words at each length). Each of the nonwords was composed of early developing phonemes and contained syllables that did not correspond to English lexical items. The latter constraint was imposed to reduce the effects that differences in vocabulary knowledge might have on performance on this task (see Dollaghan \& Campbell, 1998). The nonword-repetition task was administered to children via headphones and a high-quality audio recorder, and participants' responses were recorded. These responses were scored in terms of the percentage of consonants produced correctly. Scores were converted to standard scores based on the weighted mean and standard deviation of the available sample at second $(N=604)$ and eighth grades $(N=527)$.

\section{Results}

The subgroups' performances on measures of phonological awareness are displayed in Figure 2. Univariate ANOVA procedures were used to examine group differences. Because tests (or items) used to measure phonological awareness varied at some grades, grade level was not evaluated as a repeated measure. The results indicated that there was a significant group difference at each grade, $F \mathrm{~s}(3,243)=32.4-82.4, p<.01$. In kindergarten, Tukey honestly significant difference tests for unequal Ns showed that only the normal subgroup performed significantly different from the other subgroups $(p<.001, d s=1.03-1.29)$. In the other grades, both the normal and the SLI-only subgroups scored significantly better than the dyslexia-only and SLI/dyslexia subgroups $(p<.001, d s=1.08-2.09)$. The normal and SLIonly subgroups differed significantly from each other in second grade $(p<.05, d=0.48)$ but not in the fourth and eighth grades $(p>.05, d \mathrm{~s}=0.13-0.19)$. The dyslexiaonly and SLI/dyslexia subgroups did not perform significantly different from each other on the phonological awareness tasks at any grade tested $(p>.05, d \mathrm{~s}=$ 0.11-0.44).

Data for the nonword-repetition task are shown in Figure 3. A 4 (group) $\times 2$ (grade) mixed-model ANOVA was used to examine group differences at each grade. This analysis revealed a significant main effect of group, $F(3,242)=31.2, p<.001$, and grade, $F(1,242)=57.0, p<$ .001 . The Group $\times$ Grade interaction was not significant, $F(3,242)=1.2, p>.05$. Follow-up tests of group differences (collapsed across grades) indicated the dyslexiaonly and SLI/dyslexia subgroups did not differ significantly from each other, $F(1,242)=1.0, p>.05$, but each did differ significantly from the normal subgroup, $F \mathrm{~s}(1$, $242)=45.4$ and 55.3, $p<.001$. Results further showed that the SLI-only subgroup performed significantly better than the dyslexia-only subgroup, $F(1,242)=13.9, p<$ .001 , and the SLI/dyslexia subgroup, $F(1,242)=21.4, p$ $<.001$, but less well than the normal subgroup, $F(1,242)$ $=11.0, p<.01$.

Others have reported that language/reading group differences are most apparent on the nonword-repetition task at longer syllable lengths (Dollaghan \& Campbell, 1998). Recall that our nonword-repetition task included 16 items ranging from one to four syllables in length (4 items at each length). To examine the possible interaction between group and syllable length, we ran a 4 (group) $\times 4$ (syllable length) $\times 2$ (grade) mixedmodel ANOVA. The results showed a significant Group $\times$ Syllable Length interaction, $F(9,726)=11.2, p<.001$. 


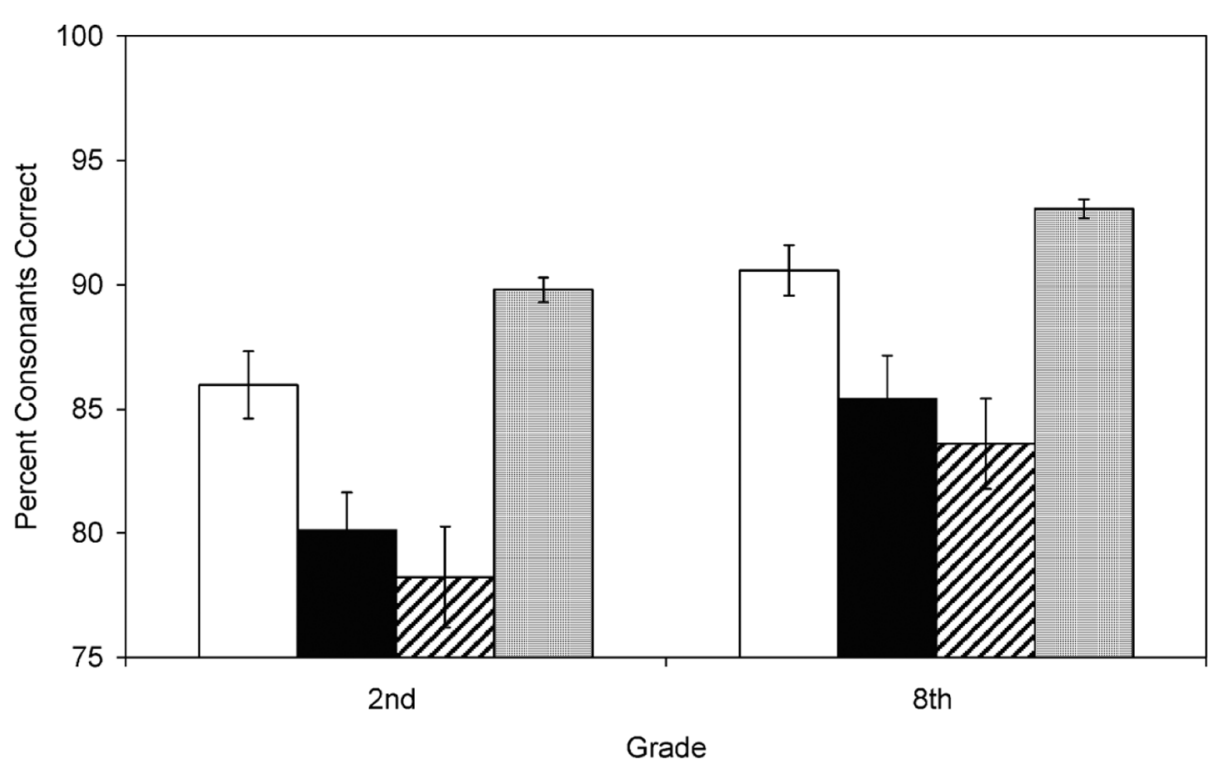

$\square$ SLI Dyslexia $\boldsymbol{\square}$ SLI/Dyslexia $\square$ Normal

Figure 3. Nonword repetition performance of subgroups in the second and eighth grades.

This significant interaction was reflective of group differences at the three- and four-syllable levels that were comparable in nature to those found on the overall measure and few group differences at the one- and two-syllable levels. This pattern was similar at both grades, and thus the three-way interaction failed to reach significance, $F(9,726)=1.7, p>.05$. Follow-up analyses $(p<$ $.01)$, collapsed across grades, indicated that at the onesyllable length the normal subgroup performed significantly better than the SLI/dyslexia subgroup; no other differences were significant. At the two-syllable length, no significant group differences were observed. Further follow-up testing showed that at both the three- and four-syllable levels the dyslexic-only and SLI/dyslexic subgroups did not differ significantly from each other, but each did differ significantly from the normal and SLI-only subgroups. Finally, we found that at the longer syllable levels the SLI-only subgroup performed significantly differently from the normal subgroup. The latter finding was indicative of the SLI-only subgroup showing mild deficits at the three- and four-syllable levels.

Several sets of post hoc analyses were undertaken to rule out factors that might have influenced subgroup differences in phonological processing. The first involved the dyslexic-only and normal subgroups. Recall that these subgroups differed significantly in terms of their mean kindergarten language composite scores. To control for this difference, we used an analysis of covariance (ANCOVA). Our results showed that when the kindergarten language composite score served as a covariate, the dyslexia-only and normal subgroups continued to differ significantly in phonological awareness, $F_{\mathrm{s}}(1,183)=13.04-60.7, p<.001$, and nonword repetition, $F(1,183)=29.6, p<.001$.
In further analyses, we found that the normal subgroup performed higher on measures of IQ than did the other subgroups. The normal subgroup's nonverbal IQ was significantly higher than that of the SLI-only subgroup in second grade $(p<.001, d=0.82)$, and the normal subgroup's estimated Full Scale IQ was significantly higher than those of the SLI-only $(p<.001, d=$ $1.18)$ and SLI/dyslexia subgroups $(p<.01, d=1.05)$ in second grade and those of all three subgroups in the fourth (SLI/dyslexia: $p<.01, d=1.06$; SLI only: $p<$ $.001, d=1.21$; dyslexia only: $p<.05, d=0.74$ ) and eighth grades (SLI/ dyslexia: $p<.01, d=1.11$; SLI only: $p<.001$, $d=0.78$; dyslexia only: $p<.05, d=0.74)$. No significant differences in nonverbal $(p>.05, d s=0.02-0.40)$ or estimated Full Scale IQ $(p>.05, d s=0.05-0.65)$ were observed between the other subgroups. To rule out the influence of IQ in comparisons involving the normal subgroup, we conducted ANCOVAs using fourth grade estimated Full Scale IQ as a covariate. The results of these comparisons were the same as those when no covariate was used, with one exception. The normal and SLI-only subgroups did not differ in nonword repetition in this ANCOVA; however, when a less restrictive measure of nonverbal IQ (either at second or eighth grade) was used as a covariate, these groups differed significantly, as they had in the original analysis.

Another set of post hoc analyses involved comparisons between the SLI-only and SLI/ dyslexia subgroups. A primary finding in this study was that these subgroups differed in phonological processing. Given the significance of this finding, it is important to rule out other subgroup differences that may have influenced this result. As noted above, the SLI-only and SLI/dyslexia subgroups did not differ in IQ. Also, recall that 
these subgroups did not differ significantly in terms of the severity of their language impairment in kindergarten. Whereas severity of language impairment was free to vary in these groups, they had almost identical mean language composite scores. Further post hoc analyses showed that these subgroups did not differ significantly on any of the language subtests that were used to form the kindergarten language composite score $(p>.05, d s=$ $0.06-0.49$ ). Kindergarten language data were also available on an experimental measure of grammatical tense marking (see Rice, Tomblin, Hoffman, Richman, \& Marquis, 2004) for approximately $60 \%$ of the participants in these subgroups. Analysis of these data indicated that the SLI-only and SLI/dyslexia subgroups performed comparably in this aspect of language $(p>.05, d=0.41)$. Additional post hoc analyses indicated that these subgroups did not differ significantly on language composite scores in second grade $(p>.05, d=0.33)$ or fourth grade $(p>.05, d=0.40)$. However, in eighth grade the SLI/dyslexia group had a significantly lower language composite score than the SLI-only subgroup $(p<.05, d$ $=0.72$ ). This latter difference could represent a difference in constitutional language abilities that was not apparent until a later grade. Alternatively, this difference could be the result of subgroup variation in reading achievement and experience.

Whereas the SLI-only and SLI/dyslexia subgroups did not generally differ in severity of language impairment, further post hoc analyses did suggest that there may have been differences in intervention history. Parents of participants with both SLI and dyslexia more often reported that these children had received clinical services in kindergarten and/or primary grades than had parents of children with SLI only, $\chi^{2}(1, N=61)=$ $55.3, p<.001$. This result is not surprising given other research showing that in clinical samples (i.e., those receiving intervention) there is a high overlap between SLI and dyslexia. Last, although we could not rule out differences in environmental influences among subgroups, we found no significant differences in mother's education between the SLI-only and SLI/dyslexia subgroups $(p>.05, d=0.33)$.

\section{Discussion}

In this study, we predicted that a phonological processing deficit would be more closely associated with dyslexia than SLI. Our results were consistent with this prediction. Children with dyslexia only and those with a combination of dyslexia and SLI (i.e., the SLI/dyslexia subgroup) performed poorly on measures of phonological awareness and nonword repetition across the grades. Children with SLI only, on the other hand, did not show significant deficits on measures of phonological processing. This subgroup, however, had lower scores than the normal subgroup on all measures of phonological processing. Although these differences were not statistically significant in all cases, they may indicate that children with SLI only, on average, have a mild deficit in phonological processing.

These various findings are consistent with a large body of research that indicates that a deficit in phonological processing is central to dyslexia (e.g., Fletcher et al., 1994). They are also in line with the most recent IDA definition of dyslexia, which proposes that a deficit in phonological processing lies at the core of the word recognition problems in the disorder (Lyon et al., 2003). Our results, however, appear to be in contrast to those linking SLI with a deficit in phonological processing. This is particularly true for the findings concerning nonword repetition. Recall that many studies have reported that children with SLI have deficits in nonword repetition (Dollaghan \& Campbell, 1998; Gathercole \& Baddeley, 1990; Kamhi \& Catts, 1986). Furthermore, problems in nonword repetition have been argued to be a potential psycholinguistic marker of SLI (Bishop et al., 1996; Conti-Ramsden et al., 2001). Our findings, however, indicate only a weak association, at most, between SLI and problems in nonword repetition.

The discrepancy between our findings and those of others concerning a link between SLI and a deficit in phonological processing can be explained largely on the basis of the comorbidity between SLI and dyslexia. In Study 1, we found that the overlap between SLI and dyslexia was greater than expected given the base rates of the two disorders. This overlap indicates that a portion of children with SLI will also have dyslexia. Furthermore, if this comorbidity involves an overlap of deficits in abilities that are continuously distributed, we might also expect that children with SLI who do not meet the criteria for dyslexia to still be lower, on average, in word reading and phonological processing than children with normal language. Thus, it seems quite possible that previous studies of SLI and nonword repetition have involved samples of children with SLI that included enough children who also had dyslexia or borderline dyslexic-like problems such that SLI groups, as a whole, would score significantly below that of control groups on nonword repetition. Indeed, in our longitudinal sample, which had rather limited overlap between SLI and dyslexia compared with other studies, the post hoc analysis indicated that when all children with SLI in kindergarten were combined (including those with SLI only, SLI and dyslexia, and those on the borderline of dyslexia; $N=106$ ), they performed significantly below that of typically developing children in nonword repetition. Also, Ellis Weismer et al. (2000) showed that children from our same longitudinal sample who were identified as having SLI in second grade scored significantly less well on the nonword-repetition task than did typically developing children. Thus, in our sample 
and in others, comorbidity with dyslexia may account in part for why children with SLI, as a group, show poor performance in nonword repetition. However, further post hoc analyses indicate that such comorbidity may not completely explain these results. These analyses showed that when we compared all children with SLI in kindergarten $(N=106)$ to all children without language impairment $(N=256)$ and covaried out differences in word reading, the groups still differed significantly in nonword repetition. This finding suggests that at least a portion of the low nonword repetition performance of children with SLI results from factors other than comorbidity with dyslexia.

Additional results from our longitudinal database provide further converging evidence related to Study 2. Tomblin et al. (2004) reported that a factor analysis of the language scores of our sample at age 7 showed that performance on phonological awareness and nonword repetition loaded on a different factor than performance on semantic and syntactic tasks. This suggests that some children may have problems in phonological processing and not in semantics and syntax (i.e., dyslexia only), and others may show the reverse pattern (i.e., SLI only). These findings are also consistent with the results of recent genetics studies. Bishop and colleagues (Adams \& Bishop, 2002; Bishop, 2001, 2005), in a twin study of SLI, found high heritability for grammatical morphology and nonword repetition; however, heritability of each of these skills was independent of the other. Furthermore, Bishop and her colleagues reported a greater genetic association (i.e., bivariate heritability) between nonword repetition and dyslexia than between grammatical morphology and dyslexia (Bishop, 2001; Bishop et al., 2004). This latter finding converges well with our results demonstrating a link between deficits in nonword repetition and dyslexia.

Whereas our results appear to be consistent with the above related findings, two issues need further consideration. One issue concerns the age at which we identified children with SLI. Many studies that have examined the relationship between SLI and phonological processing have selected participants on the basis of language performance during the postkindergarten school years (e.g., Dollaghan \& Campbell, 1998; ContiRamsden et al., 2001). We selected participants on the basis of a kindergarten language assessment (for reasons outlined in the beginning of this article); however, to be consistent with previous studies, we reanalyzed our results using school-age diagnostic criteria. In these analyses, the participants were reclassified into subgroups using criteria based on second-grade language status and second-grade word reading scores. We also regrouped participants using criteria based on fourthgrade language and fourth-grade word reading scores. The results in both cases were essentially the same. Children with dyslexia only and those with SLI/dys- lexia had significant deficits in phonological processing, whereas those with SLI only had mild problems at most. Thus, it does not appear that the grade at which a language impairment is identified influences the nature of the relationship between SLI and phonological processing.

A second issue concerns the direction of causality between problems in phonological processing and dyslexia. We have argued that our results support the view that a deficit in phonological processing underlies the word reading problems in dyslexia. However, it is possible that at least a portion of the differences in phonological processing observed between participants with dyslexia (i.e., those in the dyslexia-only and SLI/ dyslexia subgroups) and those without (normal and SLIonly subgroup) was a consequence of poor word reading. Indeed, studies have shown that word reading ability itself can influence performance in phonological processing, especially phonological awareness (Hogan, Catts, \& Little, 2005; McGuinness, McGuinness, \& Donohue, 1995). Our results showing that the SLI-only subgroup seemed to improve across grades in phonological awareness, whereas the dyslexia-only subgroup declined slightly across grades, could possibly be a reflection of the influence of reading on phonological awareness. Alternatively, this result might indicate that phonological awareness deficits are more specific to children with dyslexia than those with SLI only and, as such, are more stable over time.

\section{General Discussion}

In the beginning of this article, we offered three alternative models concerning the relationship between SLI and dyslexia. Model 1 characterizes SLI and dyslexia as variants of the same developmental language disorder but differing in the severity of the disorder (e.g., Tallal et al., 1997). Model 2 proposes that SLI and dyslexia share a comparable deficit in phonological processing and word reading problems but differ in terms of the presence/absence of oral language deficits (Bishop\& Snowling, 2004). Model 3 argues that SLI and dyslexia are distinct but comorbid disorders. The results from the present investigation are more in line with Model 3.

In Study 1, we examined the overlap between SLI and dyslexia. If either Model 1 or 2 is accurate, we should have found considerable overlap between SLI and dyslexia. Both of these proposals contend that children with SLI have problems in phonological processing and subsequent difficulties in word reading. Thus, most children with SLI should also be identified as having dyslexia. This was not the case. Our results showed a statistically significant, but limited, overlap between SLI and dyslexia. Most children with SLI in kindergarten did not have dyslexia during the school 
years. This result is more consistent with Model 3. According to this model, most affected children will have either SLI or dyslexia. A small percentage of children, however, can have both disorders as a result of comorbidity. Model 3 is further supported by Study 2. This study showed that whereas dyslexia was associated with significant deficits in phonological processing, SLI alone was generally not.

\section{Relationship Between SLI and Dyslexia}

Taken together, the findings from the present investigation support the view that SLI and dyslexia are distinct developmental disorders. According to this view, dyslexia is a developmental language disorder that is characterized by problems in phonological processing and word reading deficits. SLI, on the other hand, is a disorder involving problems in oral language, including deficits in semantics, syntax, and/or discourse processing. It is unclear from this investigation what factors may underlie SLI. The disorder may result from a specific morpho-syntactic deficit (Rice \& Wexler, 1996) and/or from some other perceptual/cognitive impairment (Miller, Kail, Leonard, \& Tomblin, 2001; Montgomery, 2000; Tallal, 2003). A problem in phonological processing, however, does not appear to be a major factor in SLI when it occurs in isolation from dyslexia.

Whereas dyslexia and SLI may best be viewed as distinct disorders, they appear to be comorbid in some children. Our results indicated that about twice as many children had both disorders than would be predicted given the base rate of either disorder. In clinical populations, we would expect even more overlap to occur. Children from the latter populations generally have more severe and widespread disorders and thus should more often meet the criteria of both disorders. Indeed, the studies we reviewed that sampled from clinical populations found a high level of overlap between SLI and dyslexia (e.g., McArthur et al., 2000; Tallal et al., 1997). Because the deficits that underlie SLI and dyslexia are likely to involve continuously distributed abilities (Dollaghan, 2004; S. E. Shaywitz, Escobar, Shaywitz, Fletcher, \& Makuch, 1992), the comorbidity of the disorders should spread its effects to the borderline of each disorder. As a result, children with SLI alone may show low normal performance in phonological processing and word reading, and children with dyslexia alone may have low normal oral language abilities. However, despite the additional overlap on the borderline of each disorder, there should be many children who meet the criteria for one disorder but are well within normal limits in abilities related to the other disorder.

The fact that SLI and dyslexia are distinct disorders is supported further by a growing body of research on poor comprehenders, that is, children who demonstrate a deficit in reading comprehension despite normal or near-normal word recognition ability. It is estimated that perhaps as many as $5 \%$ to $10 \%$ of school-age children show this reading problem (Catts, Adlof, \& Ellis Weismer, in press; Nation, 2005). Recent research indicates that these children have a wide range of deficits in oral language (Nation, Clarke, Marshall, \& Durand, 2004; Nation \& Snowling, 1997; Oakhill \& Yuill, 1996; Stothard \& Hulme, 1995). These deficits, however, are confined to nonphonological aspects of language and do not include problems in phonological awareness and phonological memory. Thus, these children appear to demonstrate the characteristics of children with SLI alone and are quite distinct from those with dyslexia. Indeed, studies have documented that nearly $50 \%$ of poor comprehenders have a history of oral language problems that are severe enough (and generally discrepant enough from nonverbal IQ) to meet the criteria of SLI (Catts et al., in press; Nation et al., 2004).

The concept of a poor comprehender is also central to one of the alternative models concerning the relationship between SLI and dyslexia. Specifically, Bishop and Snowling (2004) proposed that SLI and dyslexia typically share deficits in phonological processing and word reading but differ in that SLI is also characterized by significant oral language problems and dyslexia is not (i.e., Model 2). They acknowledged, however, that some children may have significant deficits in oral language abilities but have normal phonological processing abilities. They referred to the latter children as poor comprehenders rather than children with SLI only, as we do. Thus, the primary difference between their proposal and the one we favor is the choice of terminology. However, we believe our proposal is more consistent with traditional practice and current research findings. The term SLI has traditionally been used to describe children with oral language deficits regardless of the presence or absence of phonological processing deficits (Leonard, 1998). It has also been used to characterize children's oral language development during the preschool years and has not been dependent on reading problems. Our results suggest that at least in a population-based sample there will be many children who meet the criteria for SLI prior to school entrance but who do not have a phonological processing deficit. It would seem more appropriate to refer to these children as having SLI and acknowledge that this condition can exist by itself in some children as well as be comorbid with dyslexia in others. In such a model, the term poor comprehender would be used to refer to children with a history of SLI (as well as those without) who have specific problems in reading comprehension during the school years. 


\section{Acknowledgments}

This study was supported by a grant from the National Institute on Deafness and Other Communication Disorders (1-P50DC02726-04). The completion of this study was aided considerably by a valuable research team comprising the following: Bruce Tomblin, Xuyang Zhang, Marc Fey, Paula Buckwalter, Marlea O'Brien, Connie Ferguson, Jodi Schwartz, Juanita Limas, and Amy Kundel. Appreciation is also extended to Holly Storkel and David Slegers for their assistance.

\section{References}

Adams, C. V., \& Bishop, D. V. M. (2002, July). Genetic influences on verb morphology deficits in 6-year-old twins. Poster presented at the joint conference of the International Association for the Study of Child Language and the Symposium for Research on Children with Language Disorders, Madison, WI.

Badian, N., McAnulty, G., Duffy, G., \& Als, H. S. (1990). Prediction of dyslexia in kindergarten boys. Annals of Dyslexia, 41, 221-243.

Bedore, L. M., \& Leonard, L. B. (1998). Specific language impairment and grammatical morphology: A discriminant function analysis. Journal of Speech, Language, and Hearing Research, 41, 1185-1192.

Berkson, J. (1946). Limitations of the application of fourfold table analysis to hospital data. Biometrics, 2, 47-53.

Bishop, D. V. M. (2001). Genetic influences on language impairment and literacy problems in children: Same or different? Journal of Child Psychology and Psychiatry, 42, 189-198.

Bishop, D. V. M. (2005). DeFries-Fulker analysis of twin data with skewed distributions: Cautions and recommendations from a study of children's use of verb inflections. Behaviour Genetics, 35, 479-490.

Bishop, D. V. M., \& Adams, C. (1990). A prospective study of the relationship between specific language impairment, phonological disorders, and reading retardation. Journal of Child Psychology and Psychiatry, 31, 1027-1050.

Bishop, D. V. M., Adams, C. V., \& Norbury, C. F. (2004). Using nonword repetition to distinguish genetic and environmental influences on early literacy development: A study of 6-year-old twins. American Journal of Medical Genetics: Neuropsychiatric Genetics, 129, 94-96.

Bishop, D. V. M., North, T., \& Donlan, C. (1996). Nonword repetition as a behavioral marker for inherited language impairment: Evidence from a twin study. Journal of Child Psychology and Psychiatry, 37, 391-403.

Bishop, D. V. M., \& Snowling, M. J. (2004). Developmental dyslexia and specific language impairment: Same or different? Psychological Bulletin, 130, 858-886. Bradley, L., \& Bryant, P. E. (1983). Categorising sounds and learning to read - A causal connection. Nature, 301, 419-521.

Brady, S., Poggie, E., \& Rapala, M. M. (1989). Speech repetition abilities in children who differ in reading skill. Language and Speech, 32, 109-122.
Brady, S., Shankweiler, D., \& Mann, V. (1983). Speech perception and memory coding in relation to reading ability. Journal of Experimental Child Psychology, 35, 345-367.

Briscoe, J., Bishop, D. V. M., \& Norbury, C. F. (2001). Phonological processing, language, and literacy: A comparison of children with mild-to-moderate sensorineural hearing loss and those with specific language impairment. Journal of Child Psychology and Psychiatry, 42, 329-340.

Caron, C., \& Rutter, M. (1991). Comorbidity in child psychopathology: Concepts, issues and research strategies. Journal of Child Psychology and Psychiatry, 32, 1063-1080.

Catts, H. W. (1986). Speech production/phonological deficits in reading-disordered children. Journal of Learning Disabilities, 19, 504-508.

Catts, H. W. (1993). The relationship between speech- language impairments and reading disabilities. Journal of Speech and Hearing Research, 36, 948-958.

Catts, H. W., Adlof, S. M., \& Ellis Weismer, S. (in press). Language deficits in poor comprehenders: A case for the simple view of reading. Journal of Speech, Language, and Hearing Research.

Catts, H. W., Fey, M. E., Tomblin, J. B., \& Zhang, X. (1999). Language basis of reading and reading disabilities. Scientific Studies of Reading, 3, 331-361.

Catts, H. W., Fey, M. E., Tomblin, J. B., \& Zhang, X. (2002). A longitudinal investigation of reading outcomes in children with language impairments. Journal of Speech, Language, and Hearing Research, 45, 1142-1157.

Catts, H. W., Fey, M. E., Zhang, X., \& Tomblin, J. B. (2001). Estimating the risk of future reading difficulties in kindergarten children: A research-based model and its clinical implications. Language, Speech, and Hearing Services in Schools, 32, 38-50.

Catts, H. W., \& Kamhi, A. G. (2005). Language and reading disabilities (2nd ed.). Needham Heights, MA: Allyn \& Bacon.

Conti-Ramsden, G., Botting, N., \& Faragher, B. (2001). Psycholinguistic markers for specific language impairment (SLI). Journal of Child Psychology and Psychiatry and Allied Disciplines, 42, 741-748.

Culatta, B., Page, J., \& Ellis, J. (1983). Story retelling as a communicative performance screening tool. Language, Speech, and Hearing Services in Schools, 14, 66-74.

Dollaghan, C. A. (2004). Taxometric analyses of specific language impairment in 3- and 4-year-old children. Journal of Speech, Language, and Hearing Research, 47, 464-475.

Dollaghan, C. A., \& Campbell, T. F. (1998). Nonword repetition and child language impairment. Journal of Speech, Language, and Hearing Research, 41, 1136-1146.

Dunn, L. M., \& Dunn, L. M. (1981). Peabody Picture Vocabulary Test-Revised. Circle Pines, MN: American Guidance Service.

Dykman, R. A., \& Ackerman, P. T. (1992). Diagnosing dyslexia: IQ regression plus cut points. Journal of Learning Disabilities, 25, 574-576.

Edwards, J. D., \& Lahey, M. (1998). Nonword repetitions of children with specific language impairment: Exploration 
of some explanations for their inaccuracies. Applied Psycholinguistics, 19, 279-309.

Elbro, C. (1996). Early linguistic abilities and reading development: A review and a hypothesis. Reading and Writing: An Interdisciplinary Journal, 8, 453-485.

Ellis Weismer, S., Tomblin, J. B., Zhang, X., Buckwalter, P., Chynoweth, J. G., \& Jones, M. (2000). Nonword repetition performance in school-age children with and without language impairment. Journal of Speech, Language, and Hearing Research, 43, 865-878.

Fletcher, J. M., Shaywitz, S. E., Shankweiler, D. P., Katz, L., Liberman, I. Y., Stuebing, K. K., et al. (1994). Cognitive profiles of reading disability: Comparisons of discrepancy and low achievement definitions. Journal of Educational Psychology, 86, 6-23.

Frankenberger, W., \& Fronzaglio, K. (1991). A review of states' criteria and procedures for identifying children with learning disabilities. Journal of Learning Disabilities, 24, 495-500.

Gallagher, A., Frith, U., \& Snowling, M. J. (2000). Precursors of literacy delay among children at genetic risk of dyslexia. Journal of Child Psychology and Psychiatry and Allied Disciplines, 41, 202-213.

Gathercole, S. E., \& Baddeley, A. D. (1990). Phonological memory deficits in language disordered children: Is there a causal connection? Journal of Memory and Language, $29,336-360$.

Gayan, J., \& Olson, R. K. (2003). Genetic and environmental influences on individual differences in printed word recognition. Journal of Experimental Child Psychology, 84, 97-123.

Gillon, G. T. (2004). Phonological awareness: From research to practice. New York: Guilford Press.

Hogan, T. P., Catts, H. W., \& Little, T. (2005). The relationship between phonological awareness and reading: Implications for the assessment of phonological awareness. Language, Speech, and Hearing Services in Schools, 36, 285-293.

Hulme, C., \& Snowling, M. J. (1992). Deficits in output phonology: An explanation of reading failure? Cognitive Neuropsychology, 9, 47-72.

Joffe, V. L. (1998). Rhyming and related skills in children with specific language impairment. Cahiers de Psychologie Cognitive/Current Psychology of Cognition, 17, 479-512.

Kamhi, A. G., \& Catts, H. W. (1986). Toward an understanding of developmental language and reading disorders. Journal of Speech and Hearing Disorders, 51, 337-347.

Leonard, L. B. (1998). Children with specific language impairment. Cambridge, MA: MIT Press.

LoBello, S. G. (1991). Intelligence testing with the WISC-R. New York: Wiley.

Lyon, G. R., Shaywitz, S. E., \& Shaywitz, B. A. (2003). A definition of dyslexia. Annals of Dyslexia, 53, 1-14. Lyytinen, H., Ahonen, T., Eklund, K., Guttorm, T. K., Laakso, M. L., Leinonen, S., et al. (2001). Developmental pathways of children with and without familial risk for dyslexia dur- ing the first years of life. Developmental Neuropsychology, 20, 535-554.

Lyytinen, P., Poikkeus, A. M., Laakso, M. L., Eklund, K., \& Lyytinen, H. (2001). Language development and symbolic play in children with and without familial risk for dyslexia. Journal of Speech, Language, and Hearing Research, 44, 873-885.

McArthur, G. M., Hogben, J. H., Edwards, V. T., Heath, S. M., \& Mengler, E. D. (2000). On the "specifics" of specific reading disability and specific language impairment. Journal of Child Psychology and Psychiatry and Allied Disciplines, 41, 869-874.

McGuinness, D., McGuinness, C., \& Donohue, J. (1995). Phonological training and the alphabet principle: Evidence for reciprocal causality. Reading Research Quarterly, 30, 830-852.

Metsala, J. L., \& Walley, A. C. (1998). Spoken vocabulary growth and the segmental restructuring of lexical representations: Precursors to phonemic awareness and early reading ability. In L. C. Ehri \& J. L. Metsala (Eds.), Word recognition in beginning literacy (pp. 89-120). Mahwah, NJ: Erlbaum.

Meyer, M. S., Wood, F. B., Hart, L. A., \& Felton, R. H. (1998). Selective predictive value of rapid automatized naming in poor readers. Journal of Learning Disabilities, 31, 106-117.

Miller, C., Kail, R., Leonard, L., \& Tomblin, J. B. (2001). Speed of processing in children with specific language impairment. Journal of Speech, Language, and Hearing Research, 44, 416-433.

Montgomery, J. W. (2000). Verbal working memory and sentence comprehension in children with specific language impairments. Journal of Speech, Language, and Hearing Research, 43, 293-308.

Nathan, L., Stackhouse, J., Goulandris, N., \& Snowling, M. J. (2004). The development of early literacy skills among children with speech difficulties: A test of the "Critical Age Hypothesis." Journal of Speech, Language, and Hearing Research, 47, 377-391.

Nation, K. (2005). Connections between language and reading in children with poor reading comprehension. In $\mathrm{H}$. W. Catts \& A. G. Kamhi (Eds.), Connections between language and reading disabilities (pp. 41-54). Mahwah, NJ: Erlbaum.

Nation, K., Clarke, P., Marshall, C. M., \& Durand, M. (2004). Hidden language impairments in children: Parallels between poor reading comprehension and specific language impairments? Journal of Speech, Language, and Hearing Research, 47, 199-211.

Nation, K., \& Snowling, M. J. (1997). Individual differences in contextual facilitation: Evidence from dyslexia and poor reading comprehension. Child Development, 69, 996-1011.

Newcomer, P., \& Hammill, D. (1988). Test of Language Development-Primary (2nd ed.). Austin, TX: Pro-Ed.

Oakhill, J. V., \& Yuill, N. (1996). Higher order factors in comprehension disability: Processes and remediation. In C. 
Cornoldi \& J. V. Oakhill (Eds.), Reading comprehension difficulties (pp. 69-92). Mahwah, NJ: Erlbaum.

Paul, R. (2001). Language disorders from infancy to adolescence: Assessment and intervention. St. Louis, MO: Mosby.

Pennington, B. F., Gilger, J. W., Olson, R. K., \& DeFries, J. C. (1992). The external validity of age- versus IQ-discrepancy definitions of a reading disability: Lessons from a twin study. Journal of Learning Disabilities, 25, 562-573.

Plaza, M., Cohen, H., \& Chevrie-Muller, C. (2001). Oral language deficits in dyslexic children: Weaknesses in working memory and verbal planning. Tennet, XII, 505-512.

Raskind, W. H., Hsu, L., Berninger, V. W., Thomson, J. B., \& Wijsman, E. M. (2000). Family aggregation of dyslexia phenotypes. Behavior Genetics, 30, 385-396.

Rice, M. L., Hoffman, L., Tomblin, J. B., Richman, W. A., \& Marquis, J. (2004). Grammatical tense deficits in children with SLI and nonspecific language impairment: Relationships with nonverbal IQ over time. Journal of Speech, Language, and Hearing Research, 47, 816-834.

Rice, M. L., \& Wexler, K. (1996). Toward tense as a clinical marker of specific language impairment in Englishspeaking children. Journal of Speech and Hearing Research, 39, 1239-1257.

Rutter, M., \& Yule, W. (1975). The concept of specific reading retardation. Journal of Child Psychology and Psychiatry, 16, 181-197.

Scarborough, H. S. (1990). Very early language deficits in dyslexic children. Child Development, 61, 1728-1743.

Scarborough, H. S. (1991). Early syntactic development of dyslexic children. Annals of Dyslexia, 41, 207-220.

Scarborough, H. S. (2005). Developmental relationship between language and reading: Reconciling a beautiful hypothesis with some ugly facts. In H. W. Catts \& A. G. Kamhi (Eds.), Connections between language and reading disabilities (pp. 3-24). Mahwah, NJ: Erlbaum.

Scarborough, H. S., \& Dobrich, W. (1990). Development of children with early language delay. Journal of Speech and Hearing Research, 33, 70-83.

Share, D. L., \& Silva, P. A. (1987). Language deficits and specific reading retardation: Cause or effect? British Journal of Disorders of Communication, 22, 219-226.

Shaywitz, B. A., Fletcher, J. M., Holahan, J. M., \& Shaywitz, S. E. (1993). Discrepancy compared to low achievement definitions of reading disability: Results from the Connecticut Longitudinal Study. Journal of Learning Disabilities, 25, 639-648.

Shaywitz, S. E., Escobar, M. D., Shaywitz, B. A., Fletcher, J. M., \& Makuch, R. (1992). Evidence that dyslexia may represent the lower tail of a normal distribution of reading ability. New England Journal of Medicine, 326, 145-150.

Shaywitz, S. E., Shaywitz, B. A., Fletcher, J. M., \& Escobar, M. D. (1990). Prevalence of reading disability in boys and girls: Results of the Connecticut Longitudinal Study. Journal of the American Medical Association, 264, 998-1002.

Siegel, L. S. (1989). Is IQ irrelevant to the definition of learning disabilities? Journal of Learning Disabilities, 22, 469-478.
Silva, P. A. (1980). The prevalence, stability and significance of developmental language delay in preschool children. Developmental Medicine and Child Neurology, 22, 768-777.

Silva, P. A., Williams, S., \& McGee, R. (1987). A longitudinal study of children with developmental language delay at age three: Later intelligence, reading and behavior problems. Developmental Medicine and Child Neurology, 29, 630-640.

Snowling, M. J. (1981). Phonemic deficits in developmental dyslexia. Psychological Research, 43, 219-234.

Snowling, M. J., Bishop, D. V. M., \& Stothard, S. E. (2000). Is preschool language impairment a risk factor for dyslexia in adolescence? Journal of Child Psychology and Psychiatry and Allied Disciplines, 41, 587-600.

Snowling, M. J., Gallagher, A., \& Frith, U. (2003). Family risk of dyslexia is continuous: Individual differences in the precursors of reading skill. Child Development, 74, 358-373.

Stanovich, K. E. (1986). Matthew effects in reading: Some consequences of individual differences in the acquisition of literacy. Reading Research Quarterly, 21, 360-364.

Stanovich, K. E. (1988). Children's reading and the development of phonological awareness. Detroit, MI: Wayne State University Press.

Stanovich, K. E., \& Siegel, L. S. (1994). Phenotypic performance profile of reading-disabled children: A regressionbased test of the phonological-core variable-difference model. Journal of Educational Psychology, 86, 24-53.

Stark, R. E., \& Tallal, P. (1981). Selection of children with specific language deficits. Journal of Speech and Hearing Disorders, 46, 114-122.

Stothard, S. E., \& Hulme, C. (1995). A comparison of phonological skills in children with reading comprehension difficulties and children with decoding difficulties. Journal of Child Psychology and Psychiatry, 36, 399-408.

Tager-Flusberg, H., \& Cooper, J. (1999). Present and future possibilities for defining a phenotype for specific language impairment. Journal of Speech, Language, and Hearing Research, 42, 1275-1278.

Tallal, P. (2003). Language learning disabilities: Integrating research approaches. Current Directions in Psychological Science, 12, 206-211.

Tallal, P., Allard, L., \& Curtiss, S. (1988). Academic outcomes of language impaired children. Unpublished manuscript.

Tallal, P., Allard, L., Miller, S., \& Curtiss, S. (1997). Academic outcomes of language impaired children. In C. Hulme \& M. J. Snowling (Eds.), Dyslexia: Biology, cognition, and intervention (pp. 167-181). London: Whurr.

Tomblin, J. B., Records, N., Buckwalter, P., Zhang, X., Smith, E., \& O'Brien, M. (1997). Prevalence of specific language impairment in kindergarten children. Journal of Speech, Language, and Hearing Research, 40, 1245-1260.

Tomblin, J. B., Records, N. L., \& Zhang, X. (1996). A system for the diagnosis of specific language impairment in kin- 
dergarten children. Journal of Speech and Hearing Research, 40, 1284-1294.

Tomblin, J. B., Zhang, X., Weiss, A., Catts, H., \& Ellis- Weismer, S. (2004). Dimensions of individual differences in communication skills among primary grade children. In M. L. Rice \& S. F. Warren (Eds.), Developmental language disorders: From phenotypes to etiologies (pp. 5376). Mahwah, NJ: Erlbaum.

van Daal, V., \& van der Leij, A. (1999). Developmental dyslexia: Related to specific or general deficits? Annals of Dyslexia, 49, 71-104.

van der Bob, W. H., \& van der Pijl, J. M. L. (1997). Effects of word length and word likeness on pseudoword repetition by poor and normal readers. Applied Psycholinguistics, 18, 101-114.

Vellutino, F. R., \& Scanlon, D. M. (Eds.). (1982). Verbal processing in poor and normal readers. New York: Springer-Verlag.
Vellutino, F. R., Scanlon, D. M., \& Lyon, G. R. (2000). Differentiating between difficult-to-remediate and readily remediated poor readers: More evidence against the IQachievement discrepancy definition of reading disability. Journal of Learning Disabilities, 33, 223-238.

Wechsler, D. (1989). Wechsler Preschool and Primary Scale of Intelligence-Revised. New York: Psychological Corporation.

Wechsler, D. (1991). Wechsler Intelligence Scale for Children-III. San Antonio, TX: The Psychological Corporation.

Wimmer, H., Mayringer, H., \& Landerl, K. (2000). The double-deficit hypothesis and difficulties in learning to read a regular orthography. Journal of Educational Psychology, 92, 668-680.

Woodcock, R. (1987). Woodcock Reading Mastery TestsRevised. Circle Pines, MN: American Guidance Service. 